\title{
Interaction Between Diplodia pinea and D. scrobiculata in Red and Jack Pine Seedlings
}

\author{
O. Santamaría, D. R. Smith, and G. R. Stanosz
}

First author: Department of Ingeniería del Medio Agronómico y Forestal, Universidad de Extremadura, Ctra. de Cáceres s/n, 06007 Badajoz, Spain; and second and third authors: Department of Plant Pathology, University of Wisconsin, Madison 53706. Accepted for publication 9 October 2010

\section{ABSTRACT}

Santamaría, O., Smith, D. R., and Stanosz, G. R. 2011. Interaction between Diplodia pinea and D. scrobiculata in red and jack pine seedlings. Phytopathology 101:334-339.

Sphaeropsis sapinea sensu lato is a conifer fungal pathogen that causes shoot blight and stem cankers. Recently, the former $S$. sapinea has been divided into two species, Diplodia pinea and D. scrobiculata. The aims of the study were to determine the contribution of each species in disease development on red and jack pines by means of co-inoculations and molecular identifications, and to evaluate how the presence of each species affects the development and aggressiveness of the other. Symptom severity (distance below the inoculation site at which necrotic needles were observed) and identification length (the maximum distance from inoculation site from which either $D$. pinea or D. scrobiculata was identified using molecular methods) were recorded 4 weeks after inoculating wounded seedlings with agar plugs colonized by these pathogens. The results suggested that $D$. pinea was much more aggressive on both hosts than D. scrobiculata. When a seedling was co-inoculated with these pathogens, the symptom development appeared to be mainly due to $D$. pinea. The presence of $D$. pinea also interfered with the establishment of $D$. scrobiculata in the plant tissue. However, D. scrobiculata showed antagonism toward $D$. pinea. When both pathogens co-occurred in a single seedling, symptom severity caused by $D$. pinea was less than when D. pinea alone was present.

Additional keywords: Pinus banksiana, P. resinosa, shoot blight, tip blight.
Sphaeropsis sapinea sensu lato is a conifer fungal pathogen of worldwide distribution and importance. It has been associated with significant economic damage in nurseries, plantations, Christmas trees and ornamental plantings, and natural stands (11, 16,21). Hosts include species in at least eight coniferous genera, including many species of pines $(16,26)$. Red pine (Pinus resinosa Aiton) and jack pine (P. banksiana Lamb.), tree species with a great economical and ecological importance in the central and eastern United States, have been severely damaged in recent decades $(21,23)$. Most parts of host plants can be affected, to result in a range of disease symptoms: shoot blight, stem cankers, branch dieback, dead tops, death, and blue staining of cut wood $(21,31)$.

Two groups, A and $\mathrm{B}$, were distinguished within $S$. sapinea sensu lato (24). These were defined based on conidial morphology, cultural characteristics and virulence $(24,37)$, and molecular markers $(8,12,27,38)$. Recently, the B group has been recognized as a distinct species and assigned the name Diplodia scrobiculata J. de Wet, B. Slippers \& M. J. Wingfield (13). At the same time, the A group was named Diplodia pinea (Desmaz.) J. Kickx fil. (syn. Sphaeropsis sapinea (Fr.:Fr.) Dyko \& Sutton in Sutton) (13). D. pinea produces abundant white to gray-green aerial mycelium in culture and grows more quickly on potato dextrose agar (PDA) than D. scrobiculata, which produces white or black mycelium appressed to the agar surface. Identification and detection from colonized host organs is facilitated by use of species-specific PCR primers that allow differentiation of these pathogens from each other and closely related fungi (28). In terms of symptom development, $D$. pinea has been shown to be more aggressive than $D$. scrobiculata $(2,5)$.

Corresponding author: O. Santamaría; E-mail address: osantama@unex.es

doi:10.1094/PHYTO-07-10-0180

(C) 2011 The American Phytopathological Society
Both $D$. pinea and $D$. scrobiculata have been frequently isolated from asymptomatic tissues of several hosts, including red and jack pines $(15,18,32,33,34)$. This persistence in healthy tissues without causing any visible damage has been associated with a latent state of the pathogen (33). Latency may explain pathogen survival in the apparently healthy tree and rapid disease development under conditions that induce host stress (29). Environmental stress from a variety of sources has been shown to induce or to aggravate the damage caused by Diplodia species. Among these, water stress appears to be the most important $(4,6,30)$, although other predisposing factors, such as poor site, hail, snow, frost damage, and insects can enhance colonization by D. pinea and D. scrobiculata $(22,29,36)$.

The reported geographic and host ranges of $D$. pinea and $D$. scrobiculata are broad and overlapping. Both species also have been isolated from individual red pine plantations $(22,32)$, from a single tree (19), and even detected using molecular methods from the same small bark and wood samples (28). Those experiments indicated the potential for intimate association between $D$. pinea and D. scrobiculata within host tissues. However, relatively little is known about their local co-occurrence and the implications of this fact for the production of inoculum, disease development, and subsequent survival. Therefore, the objectives of the present study were (i) to determine the contribution of each species to disease development on red and jack pine seedlings by means of coinoculations and identification using molecular methods, and (ii) to evaluate how the presence of each species affected symptom development by the other.

\section{MATERIALS AND METHODS}

Plant material. Dormant, 1-year-old jack pine and 2-year-old red pine nursery seedlings (Wisconsin Department of Natural Resources Wilson State Nursery, Boscobel, WI) were lifted on 27 
November 2007 and transplanted into Deepot cones (conical tubes, $6.4 \mathrm{~cm}$ wide $\times 25.4 \mathrm{~cm}$ deep; Stuewe \& Sons Inc., Corvallis, OR) in a soil mix $(1: 1, \mathrm{vol} / \mathrm{vol})$ of Plainfield sand (containing $89 \%$ sand and $7 \%$ silt) from a 24-year-old red pine plantation in central Wisconsin and Fafard Growing Mix no. 2 (Conrad Fafard Inc., Inkerman, New Brunswick, Canada). Red pine seedlings had a mean stem height of $16.9 \mathrm{~cm} \pm 0.3$ standard error (SE) and jack pine seedlings had a mean stem height of $26.8 \mathrm{~cm} \pm 0.6 \mathrm{SE}$ at the time transplanted. Seedlings were placed in a greenhouse supplemented with artificial light (maximum recorded ambient greenhouse photon flux density was $1,560 \mu \mathrm{mol}$. $\mathrm{s}^{-1} \cdot \mathrm{m}^{-2}$; supplemental photon flux density averaged $132 \mu \mathrm{mol}$. $\mathrm{s}^{-1} \cdot \mathrm{m}^{-2}$ ) to provide a $16-\mathrm{h}$ photoperiod. The seedlings were watered to field capacity every 2 to 3 days. The temperature and humidity in the greenhouse were: mean temperature (T) $25.8^{\circ} \mathrm{C} \pm$ $0.6 \mathrm{SE}$, mean relative humidity $(\mathrm{RH}) 30.1 \% \pm 1.3 \mathrm{SE}$ during trial 1 of the jack pine experiment; $\mathrm{T}=27.9^{\circ} \mathrm{C} \pm 0.9 \mathrm{SE}, \mathrm{RH}=27 \% \pm$ 1.7 $\mathrm{SE}$ during trial 2 in jack pine; $\mathrm{T}=33.1^{\circ} \mathrm{C} \pm 0.9 \mathrm{SE}, \mathrm{RH}=$ $14.3 \% \pm 1.8 \mathrm{SE}$ during trial 1 in red pine; and $\mathrm{T}=35.7^{\circ} \mathrm{C} \pm$ $0.6 \mathrm{SE}, \mathrm{RH}=12.2 \% \pm 1.2 \mathrm{SE}$ during trial 2 in red pine experiment.

Inoculations. Mycelial inoculum was produced for two monoconidial isolates of each species collected from various pine species and locations in the northcentral United States (Table 1). The elongating, asymptomatic terminal shoot of each seedling was inoculated in the greenhouse approximately 11 weeks after transplanting in the case of red pine, and 6 weeks for jack pine. Five seedlings per treatment combination (isolate and fungal species) were used in each of two trials separated by 2 weeks. Thus, in each trial five seedling of each tree species were inoculated in each of the following treatments: (i) $\mathrm{P} 1+\mathrm{S} 1$, (ii) $\mathrm{P} 1+\mathrm{S} 2$, (iii) $\mathrm{P} 2+\mathrm{S} 1$, (iv) $\mathrm{P} 2+\mathrm{S} 2$, (v) $\mathrm{P} 1+\mathrm{P} 1$, (vi) $\mathrm{P} 2+\mathrm{P} 2$, (vii) $\mathrm{S} 1+\mathrm{S} 1$, (viii) $\mathrm{S} 2+\mathrm{S} 2$, and (ix) agar $\mathrm{A}+\mathrm{A}$ (or 45 seedlings per tree species per trial). All seedlings were assigned randomly to a particular treatment.

On each shoot, two wounds (in the opposite sides of the shoot) were made by removing a needle fascicle per side (by a sterile scalpel cut flush to the stem) approximately $2 \mathrm{~cm}$ below the shoot apex. Inoculum plugs $4 \mathrm{~mm}$ in diameter were cut from the margin of an actively growing culture on PDA (Becton, Dickinson and Co., Sparks, MD) and placed on each of the two wounds. Another five nonwounded seedlings for each host were incorporated in the experiments as additional controls but those were not included in the statistical analyses. Parafilm (Pechiney Plastic Packaging, Menasha, WI) was wrapped around the shoots for 7 days.

Four weeks after inoculation, the distances below the inoculation site at which necrotic needles and cankers were present were measured (symptom severity). After needles were removed, 1-cm-long segments, centered at $0,3,6,9,12$, and $15 \mathrm{~cm}$ below the inoculation site, were aseptically removed and stored at $-20^{\circ} \mathrm{C}$ for later molecular detection of pathogen species. Additionally, $10 \%$ of seedlings that had not been inoculated with either pathogen were similarly analyzed for the presence of Diplodia species.

Molecular identifications. The technique used allowed determination of the presence of either or both Diplodia species in the same plant segment. Fungal DNA was extracted directly from the plant cross sections by using the slightly modified method of Cubero et al. (10) outlined in Smith and Stanosz (28). This method uses an extraction buffer containing hexadecyltrimethylammonium bromide (CTAB) to remove polysaccharides and polyvinylpolypyrrolidone (PVPP) to remove polyphenols, and employs two chloroform extractions to remove proteins. The extracted DNA was amplified using species-specific mitochondrial small subunit rDNA primers (28), and presence of amplified DNA fragments was verified on $0.7 \%$ agarose gels in TBE buffer. Primer sequences and detailed procedures were provided by Smith and Stanosz (28). Positive and negative controls were used in the amplifications to ensure that Diplodia DNA could be detected if present and that no false positives occurred due to con- tamination. Sections from each seedling were processed in order starting with the inoculation site and proceeding downward. If the pathogen was not detected in two consecutive sections, no further sections were processed.

Statistical analysis. Symptom severity was analyzed by twofactor analysis of variance (ANOVA) with interaction. Factors used as main effects were treatment and trial. Fisher's least significant difference was used for multiple comparison among treatments by means of the general linear model procedure of SAS (Statistical Analysis Software version 9.1.3, SAS Institute Inc., Cary, NC) when significant differences were found in the analysis of variance table. The $\ln (x+1)$ transformation of the response variable was used to stabilize the residual variance, although back-transformed values are presented in tables and figures for clarification. Assumptions of normality and homoscedasticity were assured by Kolmogorov-Smirnov and Levene's tests, respectively.

Spearman's coefficient of rank correlation was used to examine relationships between symptom severity and the farthest cross section from inoculation site from which either $D$. pinea or $D$. scrobiculata was identified (identification length). In the case of D. pinea, the identification length was also used as a response variable to make comparisons among treatments by using the Kruskal-Wallis test of equality of medians. A chi-square goodness-of-fit test was used to compare treatments by analyzing the frequency variable (percentage of seedlings from which $D$. scrobiculata was identified). All the nonparametric analyses were performed using Minitab for Windows version 14 (Minitab Inc., State College, PA). All the analyses were carried out separately for both red and jack pine since those were separate experiments.

\section{RESULTS}

Inoculated seedlings of both tree species produced symptoms similar to those reported for seedlings in field and nursery studies, including necrotic needles, stem cankers, and crooked and dead shoot tips. Symptoms were observed in $100 \%$ of the seedlings inoculated with $D$. pinea, in $60 \%$ of the seedlings inoculated with D. scrobiculata, and in $95 \%$ of the seedlings inoculated with both pathogens. No symptoms developed on wounded or nonwounded control seedlings of either host.

In jack pine, the two-factor analyses of variance of the symptom severity (distance below the inoculation site at which necrotic needles were present) indicated significant effect of the treatment $(F=50.75, P<0.01)$, but not of the trial $(F=1.92, P=0.170)$. Thus, the multiple comparison of the treatments was performed with the pooled data of the two trials. Symptom severity in jack pine was greater on seedlings inoculated with isolates of $D$. pinea than on seedlings inoculated with isolates of D. scrobiculata (Fig. 1). Symptom severity on seedlings inoculated with the isolate $S 2$ of D. scrobiculata was not significantly different from that on control seedlings. It was observed that symptom severity also differed between the two isolates of $D$. pinea. On seedlings inoculated with the most aggressive isolate (P1), there were not

TABLE 1. Origin of Diplodia isolates used to inoculate red and jack pine seedlings

\begin{tabular}{llll}
\hline Isolate $^{\mathrm{a}}$ & Isolate no. $^{\mathrm{b}}$ & \multicolumn{1}{c}{ Pine host } & Geographic origin \\
\hline P1 & 411 & Pinus resinosa & Clearwater Co., MN \\
P2 & $04-126$ & Pinus banksiana & Wood Co., WI \\
S1 & 124 & Pinus banksiana & Jackson Co., WI \\
S2 & 462 & Pinus resinosa & Clearwater Co., MN \\
\hline
\end{tabular}

a Species and isolate number: P (Diplodia pinea), S (Diplodia scrobiculata). The isolates were previously characterized according to the specific primers given by Smith and Stanosz (28).

${ }^{\mathrm{b}}$ Culture collection numbers of M. A. Palmer (3-digit number) or G. R. Stanosz (04-Xxx). 
statistical differences in the symptom severity between seedlings inoculated only with P1 and those inoculated with P1 in combination with either isolate of $D$. scrobiculata (Fig. 1). However, on seedlings inoculated with the less aggressive isolate of $D$. pinea (P2), the co-inoculation of these fungal species into the seedling significantly reduced symptom severity in comparison to that caused by P2 when it was inoculated alone (Fig. 1).

In the case of red pine seedlings, two-way ANOVA of the symptom severity showed a significant effect of the treatment $(F=15.89, P<0.01)$, and trial $(F=16.29, P<0.01)$, but not of their interaction $(F=0.34, P=0.88)$. Therefore, a multiple comparison was performed separately for each trial (Fig. 2). As in the case of jack pine, isolates ranked in the same order in relation to their aggressiveness, although in general terms, symptom severity was lower in red pine than in jack pine. In red pine, it was also observed that the presence of either isolate of D. scrobiculata in the seedling reduced the symptom severity caused by either isolate of $D$. pinea (except in trial 1 for $\mathrm{P} 2$ isolate), although in red pine, the differences between treatments were not as great as for jack pine (Fig. 2).

Data from the farthest segments from inoculation site from which $D$. pinea was identified using molecular methods (identi- fication length) are summarized in Table 2. D. pinea was identified in $98 \%$ of the seedlings inoculated with $D$. pinea. Additionally, it was also recorded in three seedlings (from a total of 12 seedlings analyzed) which had not been inoculated with $D$. pinea. In 15 seedlings (from a total of 120), D. pinea was identified in a segment farther than the distance below the inoculation site at which necrotic needles were present, although the correlation between identification length and symptom severity was very high (Pearson's coefficient $=0.87 ; P$ value $<0.001)$. D . scrobiculata was identified in $72 \%$ of the seedlings inoculated with $D$. scrobiculata, although, it was detected in a segment beyond the segment centered at the inoculation site only once. Therefore, the correlation between identification length and symptom severity was very low for $D$. scrobiculata (Pearson's coefficient $=0.12$; $P$ value $<0.419)$. Additionally, it was also detected in one control seedling (from a total of 12 seedlings analyzed) which had not been inoculated with $D$. scrobiculata.

The Kruskal-Wallis test performed on the identification length for $D$. pinea revealed significant differences between isolates of D. pinea, but not between treatments for each $D$. pinea isolate when analyzed separately (Table 3). When the frequency variable (percentage of seedlings from which $D$. scrobiculata was identi-

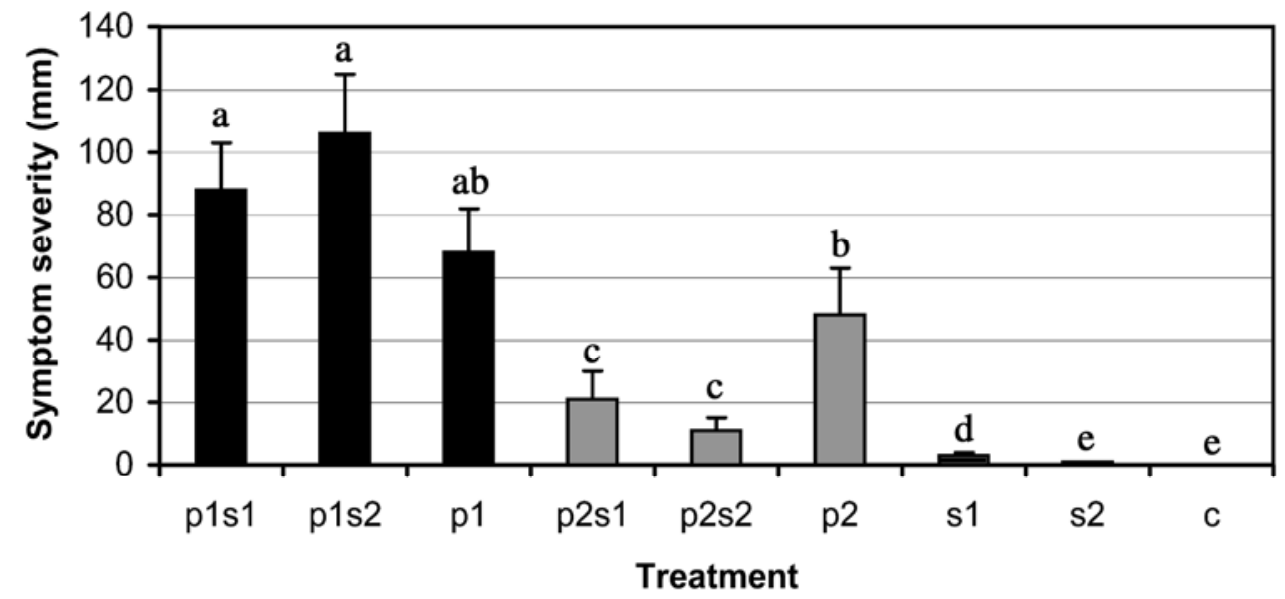

Fig. 1. Mean symptom severity (distance below the inoculation site at which necrotic needles were present) caused by isolates of Diplodia pinea (p1, p2), D. scrobiculata (s1, s2), both (p1s1...), or controls (c) for each treatment on jack pine seedlings. Averages with the same letter are not significantly different according to Fisher's least significant difference test at a significant level of 0.05 . Vertical bars indicate standard error.

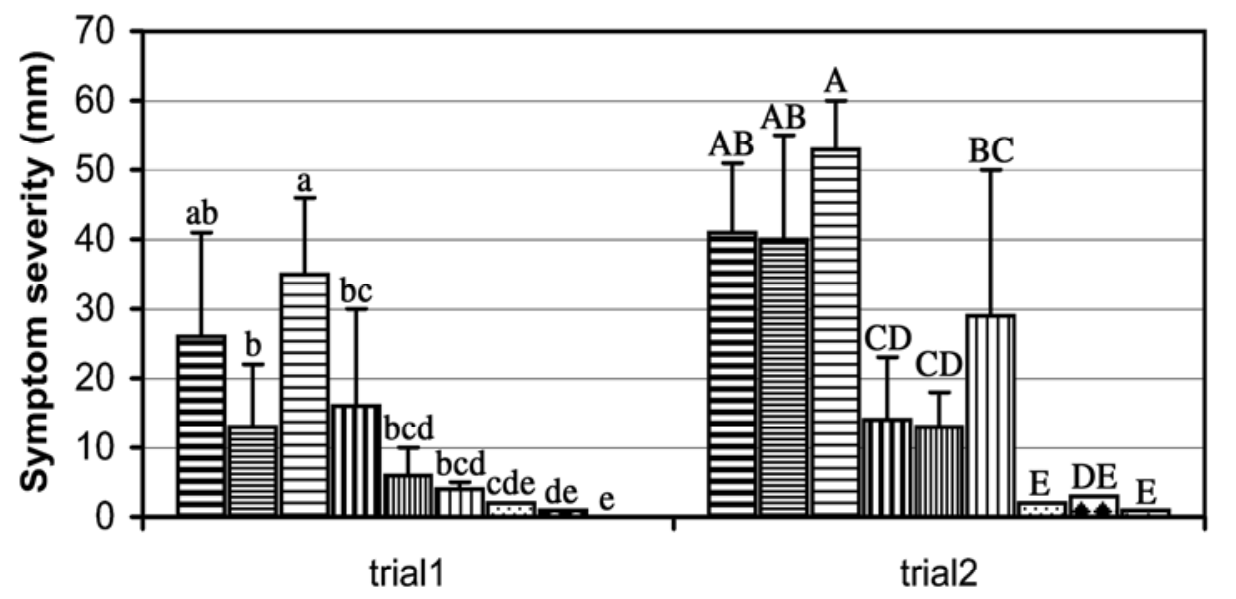

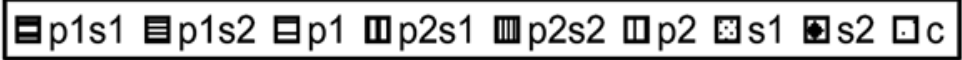

Fig. 2. Mean symptom severity (distance below the inoculation site at which necrotic needles were present) caused by isolates of Diplodia pinea (p1, p2), D. scrobiculata (s1, s2), both (p1s1...), or controls (c) for each treatment and for each trial on red pine seedlings. Averages with the same letter are not significantly different according to Fisher's least significant difference test at a significant level of 0.05 . Vertical bars indicate standard error. 
fied) was analyzed by means of a chi-square goodness-of-fit test (Table 4), it was observed that there were significant differences between trials. In trial $1, D$. scrobiculata was identified on both hosts with the same statistical frequency in seedlings inoculated only with $D$. scrobiculata as in those inoculated with $D$. scrobiculata in combination with $D$. pinea. However in trial 2 , it was observed that the presence of $D$. pinea in seedlings of both hosts reduced the percentage of seedlings from which $D$. scrobiculata was identified (Table 4).

\section{DISCUSSION}

Inoculations with $D$. pinea isolates resulted in greater severity of symptoms than inoculations with $D$. scrobiculata isolates on seedlings of red and jack pine. This result agrees well with previous studies $(5,7)$ which used a similar inoculation technique on seedlings of a variety of hosts. However in Blodgett and Stanosz (5), D. scrobiculata was more aggressive in jack pine and $D$. pinea in red pine. In our study, although results are not statistically comparable since they were obtained in separate experiments, jack pine appeared to be the most susceptible host for both pathogen species.

The correlation analysis performed between symptom severity and the farthest segment from inoculation site from which either $D$. pinea or D. scrobiculata was identified using molecular methods suggests that, when both pathogens were inoculated in the same seedling, $D$. pinea was mainly responsible for the necrosis length observed. This was consistent with the greater aggressiveness showed by $D$. pinea. The lower symptom severity when both species were inoculated compared with when $D$. pinea alone was inoculated suggests a potential antagonism between both pathogens. This may have very important implications, given the co-occurrence of $D$. pinea and D. scrobiculata in nature (19, $22,28,32$ ). Even in the present study, both pathogens were identified from a 1-cm-long shoot segment obtained from a noninoculated jack pine seedling. It would be very interesting to develop further studies to investigate whether disease incidence or severity is lower in plantations in which both pathogens occur compared with those where just one pathogen is present.
This result should be considered cautiously, however, because the reduction of the symptom severity caused by $D$. pinea when D. scrobiculata was also present was not always statistically significant. One possible explanation for this lack of significance could be related to the variability recorded among the repetitions. This great variation could in part be a consequence of the natural presence of both pathogens, in a latent state, in the seedlings used. Detection of S. sapinea sensu lato from 20 to $85 \%$ of asymptomatic samples has previously been reported $(14,15$, $18,32,33)$. Even in the present study, $D$. pinea occurred asymptomatically in $25 \%$ of the noninoculated seedlings and D. scrobiculata in $8 \%$. Despite this natural presence of the pathogen in the seedlings of our experiments, control seedlings did not show any symptoms. Lack of disease development in these seedlings may have been due to the favorable conditions provided for seedling growth, in contrast to stressful conditions that have been demonstrated to release $D$. pinea from latency to cause disease $(29,30)$. Proliferation of the previously latent pathogen in seedlings which we also inoculated could result in overestimation of symptom severity due to the stress caused by inoculations to the plants.

This natural latency also may have affected the molecular identifications of both pathogens in the stem segments and may explain several unexpected findings. For example, in several

TABLE 4. Percentage of seedlings from which Diplodia scrobiculata was identified by using molecular methods ${ }^{\mathrm{a}}$

\begin{tabular}{lcccc}
\hline & & \multicolumn{3}{c}{ Percentage (range) } \\
\cline { 3 - 5 } Host species & Trial & $\begin{array}{c}\text { D. scrobiculata } \\
+ \text { D. pinea }\end{array}$ & D. scrobiculata & $P$ \\
\hline Jack pine & 1 & $85(60-100)$ & $90(80-100)$ & 0.7055 \\
& 2 & $55(0-100)$ & $80(60-100)$ & 0.0314 \\
$P$ & & 0.0112 & 0.4431 & \\
Red pine & 1 & $80(60-100)$ & $100($ all 100) & 0.136 \\
$P$ & 2 & $45(20-60)$ & $70(40-100)$ & 0.0197 \\
& & 0.0017 & 0.0184 & \\
\hline
\end{tabular}

a Values of $P$ for comparisons between those percentages by using a chisquare goodness-of-fit test.

TABLE 2. Number of seedlings from which Diplodia pinea was identified using molecular methods from stem segments centered at $0,3,6,9,12$, or $15 \mathrm{~cm}$ from the site of inoculation

\begin{tabular}{|c|c|c|c|c|c|c|c|c|c|c|c|c|c|}
\hline \multirow[b]{3}{*}{ Treatment } & \multirow[b]{3}{*}{ Trial } & \multicolumn{12}{|c|}{ Distance from site of inoculation $(\mathrm{cm})$} \\
\hline & & \multicolumn{6}{|c|}{ Jack pine segments } & \multicolumn{6}{|c|}{ Red pine segments } \\
\hline & & 0 & 3 & 6 & 9 & 12 & 15 & 0 & 3 & 6 & 9 & 12 & 15 \\
\hline \multirow[t]{2}{*}{ P1S1 } & 1 & 5 & 4 & 3 & 3 & 1 & 1 & 5 & 2 & 2 & 0 & 0 & 0 \\
\hline & 2 & 5 & 5 & 4 & 4 & 3 & 1 & 5 & 3 & 0 & 0 & 0 & 0 \\
\hline \multirow[t]{2}{*}{ P1S2 } & 1 & 5 & 5 & 5 & 4 & 2 & 2 & 5 & 1 & 0 & 0 & 0 & 0 \\
\hline & 2 & 5 & 4 & 5 & 2 & 1 & 0 & 4 & 3 & 1 & 0 & 0 & 0 \\
\hline \multirow[t]{2}{*}{ P1P1 } & 1 & 5 & 4 & 2 & 1 & 1 & 0 & 5 & 3 & 0 & 0 & 0 & 0 \\
\hline & 2 & 4 & 5 & 4 & 3 & 1 & 0 & 5 & 4 & 2 & 0 & 0 & 0 \\
\hline \multirow[t]{2}{*}{$\mathrm{P} 2 \mathrm{~S} 1$} & 1 & 5 & 0 & 0 & 0 & 0 & 0 & 5 & 1 & 1 & 0 & 0 & 0 \\
\hline & 2 & 5 & 1 & 2 & 1 & 0 & 0 & 4 & 1 & 0 & 0 & 0 & 0 \\
\hline \multirow[t]{2}{*}{$\mathrm{P} 2 \mathrm{~S} 2$} & 1 & 5 & 0 & 0 & 0 & 0 & 0 & 5 & 0 & 0 & 0 & 0 & 0 \\
\hline & 2 & 5 & 2 & 0 & 2 & 0 & 0 & 5 & 0 & 0 & 0 & 0 & 0 \\
\hline \multirow[t]{2}{*}{$\mathrm{P} 2 \mathrm{P} 2$} & 1 & 5 & 1 & 1 & 1 & 1 & 1 & 5 & 0 & 0 & 0 & 0 & 0 \\
\hline & 2 & 5 & 4 & 2 & 1 & 0 & 0 & 5 & 1 & 0 & 1 & 0 & 0 \\
\hline
\end{tabular}

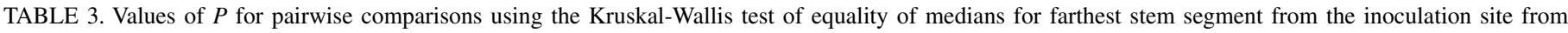
which Diplodia pinea was identified using molecular methods: jack pine data (below the diagonal) and red pine data (above the diagonal)

\begin{tabular}{|c|c|c|c|c|c|c|}
\hline Treatment & P1S1 & P1S2 & P1P1 & P2S1 & $\mathrm{P} 2 \mathrm{~S} 2$ & $\mathrm{P} 2 \mathrm{P} 2$ \\
\hline P1S1 & $\ldots$ & 0.460 & 0.328 & 0.144 & 0.013 & 0.102 \\
\hline P1S2 & 0.969 & $\ldots$ & 0.088 & 0.492 & 0.135 & 0.427 \\
\hline P1P1 & 0.313 & 0.229 & $\ldots$ & 0.018 & 0.001 & 0.009 \\
\hline $\mathrm{P} 2 \mathrm{~S} 1$ & 0.002 & 0.001 & 0.005 & $\ldots$ & 0.543 & 0.957 \\
\hline $\mathrm{P} 2 \mathrm{~S} 2$ & 0.003 & 0.002 & 0.008 & 0.914 & $\ldots$ & 0.317 \\
\hline $\mathrm{P} 2 \mathrm{P} 2$ & 0.037 & 0.010 & 0.095 & 0.214 & 0.248 & $\ldots$ \\
\hline
\end{tabular}


samples, $D$. pinea was detected in segments below other negative segments, indicating a possible latent Diplodia in those farther sections. In other samples, $D$. pinea was identified farther from the inoculation site than the necroses length recorded in the corresponding seedling. This result could be also explained by latent infections since it has been demonstrated in other studies (5) that symptom development, expressed as mean distance below the inoculation site with necrotic needles, was very positively correlated with distance of detection. A certain antagonistic effect between $D$. pinea and $D$. scrobiculata appeared to be reflected in the results of detection using molecular methods, because the presence of $D$. scrobiculata in the samples was clearly less frequent in seedlings also inoculated with $D$. pinea compared with those seedlings inoculated only with $D$. scrobiculata.

Among the three types of interactions between antagonistic organisms proposed by Adams (1), competition, antibiosis, and hyperparasitism, the former could be the most important mechanism between both pathogens. However, antibiosis could also be acting since $S$. sapinea sensu lato has been shown to produce metabolites with antifungal activity (9). With the experimental methodology followed to perform the present study it was not possible to determine if hyperparasitism was or was not an important mechanism in this antagonistic interaction, although it may be unlikely since it has not been described for Diplodia species so far. Another possibility could be hypovirulence, which has been described to take place for several others fungal pathogens like Cryphonectria parasitica (Murril) Barr. (17). Hypovirulence is due to a double-stranded (ds)RNA virus which infects fungal cells. Although hypovirulence has not been described for Diplodia species, dsRNA of several virus families has been found infecting Diplodia isolates (25) at a high frequency. Steenkamp et al. (35) identified viral dsRNA in $32 \%$ of the Diplodia isolates analyzed. Therefore, the frequency and the type of dsRNA virus present in $D$. pinea and $D$. scrobiculata and their relationship with virulence may deserve further investigations.

Systemic induced resistance (SIR) is a host defense mechanism which has also been proposed by several authors $(3,20)$ to explain why inoculations with $D$. scrobiculata reduced the symptom severity on seedlings inoculated later with $D$. pinea. However in such studies, $D$. scrobiculata was inoculated several weeks before inoculating with $D$. pinea, because plants need some time to produce the defensive action. Therefore, the reduction of symptom severity caused by $D$. pinea when $D$. scrobiculata is also inoculated into the same seedling at the same time, as it is our case, could not be explained by this mechanism of SIR. The effect caused by $D$. scrobiculata in the defense system of the plant could only be used preventively on healthy trees, since it has no curative properties (20). In the same sense, Palmer (22) affirmed that no evidence suggested that $D$. scrobiculata was related to tree recovery.

In conclusion, the results presented here suggested that, when both $D$. pinea and $D$. scrobiculata co-occurred in a single plant, the symptom development was mainly due to $D$. pinea. Furthermore, D. scrobiculata showed some antagonism toward D. pinea, since when both pathogens co-occurred in a single seedling, symptom severity caused by $D$. pinea was lower than that caused when $D$. pinea was acting alone. The presence of $D$. pinea made difficult the establishment of $D$. scrobiculata in the plant tissue.

\section{ACKNOWLEDGMENTS}

This research was partially supported by a grant provided by the Ministry of Culture and Science of Spain (Program: José Castillejo) and by the Department of Plant Pathology of the University of Wisconsin-Madison. We thank the Wisconsin Department of Natural Resources for seedlings, and J. A. Stanosz and L. Gardiner for technical assistance.

\section{LITERATURE CITED}

1. Adams, P. B. 1990. The potential of mycoparasites for biological control of plant diseases. Annu. Rev. Phytopathol. 28:59-72.

2. Blodgett, J. T., and Bonello, P. 2003. The aggressiveness of Sphaeropsis sapinea on Austrian pine varies with isolate group and site of infection. Forest Pathol. 33:15-19.

3. Blodgett, J. T., Eyles, A., and Bonello, P. 2007. Organ-dependent induction of systemic resistance and systemic susceptibility in Pinus nigra inoculated with Sphaeropsis sapinea and Diplodia scrobiculata. Tree Physiol. 27:511-517.

4. Blodgett, J. T., Kruger, E. L., and Stanosz, G. R. 1997. Sphaeropsis sapinea and water stress in a red pine plantation in central Wisconsin. Phytopathology 87:429-434.

5. Blodgett, J. T., and Stanosz, G. R. 1997. Sphaeropsis sapinea morphotypes differ in aggressiveness, but both infect nonwounded red or jack pines. Plant Dis. 81:143-147.

6. Blodgett, J. T., and Stanosz, G. R. 1998. Monoterpene and phenolic compound concentrations in water-stressed red pine inoculated with Sphaeropsis sapinea. Phytopathology 88:245-251.

7. Blodgett, J. T., and Stanosz, G. R. 1999. Differences in aggressiveness of Sphaeropsis sapinea RAPD marker group isolates on several conifers. Plant Dis. 83:853-856.

8. Burguess, T., and Wingfield, M. J. 2001. Simple sequence repeat markers distinguish among morphotypes of Sphaeropsis sapinea. Appl. Environ. Microbiol. 67:354-362.

9. Cabras, A., Mannoni, M. A., Serra, S., Andolfi, A., Fiore, M., and Evidente, A. 2006. Occurrence, isolation and biological activity of phytotoxic metabolites produced in vitro by Sphaeropsis sapinea, pathogenic fungus of Pinus radiata. Eur. J. Plant Pathol. 115:187-193.

10. Cubero, O. F., Crespo, A., Fatehi, J., and Bridge, P. D. 1999. DNA extraction and PCR amplification method suitable for fresh, herbariumstored, lichenized, and other fungi. Plant Syst. Evol. 216:243-249.

11. Davison, E. M., Tay, F. C. S., and Peroni, D. 1991. Sphaeropsis sapinea on pines in Western Australia. Australas. Plant Pathol. 20:31.

12. De Wet, J., Burgess, T., Slippers, B., Preisig, O., Wingfield, B. D., and Winfield, M. J. 2000. Characterization of Sphaeropsis sapinea isolates from South Africa, Mexico and Indonesia. Plant Dis. 84:151-156.

13. De Wet, J., Burgess, T., Slippers, B., Preisig, O., Wingfield, B. D., and Winfield, M. J. 2003. Multiple gene genealogies and microsatellite markers reflect relationships between morphotypes of Sphaeropsis sapinea and distinguish a new species of Diplodia. Mycol. Res. 107:557566.

14. Flowers, J., Hartman, J., and Vaillancourt, L. 2003. Detection of latent Sphaeropsis sapinea infection in Austrian pine tissues using nestedpolymerase chain reaction. Phytopathology 93:1471-1477.

15. Flowers, J., Nuckles, E., Hartman, J., and Vaillancourt, L. 2001. Latent infection of Austrian and Scots pine tissues by Sphaeropsis sapinea. Plant Dis. 85:1107-1112.

16. Gibson, I. A. S. 1979. Diseases of forest trees widely planted as exotics in the tropic and Southern Hemisphere. Part II. The Genus Pinus. Commonwealth Mycological Institute, Kew, England.

17. Heiniger, U., and Rigling, D. 1994. Biological control of chestnut blight in Europe. Annu. Rev. Phytopathol. 32:581-599.

18. Maresi, G., Luchi, N., Pinzani, P., Pazzagli, M., and Capretti, P. 2007. Detection of Diplodia pinea in asymptomatic pine shoots and its relation to the normalized insolation index. Forest Pathol. 37:272-280.

19. Morelet, P. M., and Chandelier, P. 1993. Sur un cas de variabilité chez Sphaeropsis sapinea. Eur. J. Forest Pathol. 23:317-320.

20. Muñoz, Z., Moret, A., and Garcés, S. 2008. The use of Verticillium dahliae and Diplodia scrobiculata to induce resistance in Pinus halepensis against Diplodia pinea infection. Eur. J. Plant Pathol. 120:331337.

21. Nicholls, T. H., and Ostry, M. E. 1990. Sphaeropsis sapinea cankers on stressed red and jack pines in Minnesota and Wisconsin. Plant Dis. 74:5456.

22. Palmer, M. A. 1991. Isolate types of Sphaeropsis sapinea associated with main stem cankers and top-kill of Pinus resinosa in Minnesota and Wisconsin. Plant Dis. 75:507-510.

23. Palmer, M. A., and Nicholls, T. H. 1985. Shoot blight and collar rot of Pinus resinosa caused by Sphaeropsis sapinea in forest tree nurseries. Plant Dis. 69:739-740.

24. Palmer, M. A., Stewart, E. L., and Wingfield, M. J. 1987. Variation among isolates of Sphaeropsis sapinea in the North Central United States. Phytopathology 77:944-948.

25. Preisig, O., Wingfield, B. D., and Wingfield, M. J. 1998. Coinfection of a fungal pathogen by two distinct double-stranded RNA viruses. Virology 252:399-406.

26. Punithalingam, E., and Waterson, J. M. 1970. Diplodia pinea. CMI Descriptions of Plant Pathogenic Fungi and Bacteria 273:1-2. 
27. Smith, D. R., and Stanosz, G. R. 1995. Confirmation of two distinct populations of Sphaeropsis sapinea in the north central United States using RAPDs. Phytopathology 85:699-704.

28. Smith, D. R., and Stanosz, G. R. 2006. A species-specific PCR assay for detection of Diplodia pinea and D. scrobiculata in dead red and jack pines with collar rot symptoms. Plant Dis. 90:307-313.

29. Smith, H., Wingfield, M. J., and Coutinho, T. A. 2002. The role of latent Sphaeropsis sapinea infections in post-hail associated dieback of Pinus patula. Forest Ecol. Manag. 164:177-184.

30. Stanosz, G. R., Blodgett, J. T., Smith, D. R., and Kruger, E. L. 2001. Water stress and Sphaeropsis sapinea as a latent pathogen of red pine seedlings. New Phytol. 149:531-538.

31. Stanosz, G. R., and Cummings-Carlson, J. 1996. Association of mortality of recently planted seedlings and established saplings in red pine plantations with Sphaeropsis collar rot. Plant Dis. 80:750-753.

32. Stanosz, G. R., Smith, D. R., and Albers, J. S. 2005. Surveys for asymptomatic persistence of Sphaeropsis sapinea on or in stems of red pine seedlings from seven Great Lakes region nurseries. Forest Pathol. 35:233-244.
33. Stanosz, G. R., Smith, D. R., Guthmiller, M. A., and Stanosz, J. C. 1997. Persistence of Sphaeropsis sapinea on or in asymptomatic shoots of red and jack pines. Mycologia 89:525-530.

34. Stanosz, G. R., Smith, D. R., and Leisso, R. 2007. Diplodia shoot blight and asymptomatic persistence of Diplodia pinea on or in stems of jack pine nursery seedlings. Forest Pathol. 37:145-154.

35. Steenkamp, E. T., Wingfield, B. D., Swart, W. J., and Wingfield, M. J. 1998. Double-stranded RNA and associated virulence in South African isolates of Sphaeropsis sapinea. Can. J. Bot. 76:1412-1417.

36. Swart, W. J., Wingfield, M. J., and Knox-Davies, P. S. 1987. Factors associated with Sphaeropsis sapinea infection of pine trees in South Africa. Phytophylactica 19:505-510.

37. Wang, C. G., Blanchette, R. A., Jackson, W. A., and Palmer, M. A. 1985 Differences in conidial morphology among isolates of Sphaeropsis sapinea. Plant Dis. 69:838-841.

38. Zhou, S., Smith, D. R., and Stanosz, G. R. 2001. Differentiation of Botryosphaeria species and related anamorphic fungi using inter simple or short sequence repeat (ISSR) fingerprinting. Mycol. Res. 105:919-926. 